\title{
Antimalarial combination therapies increase gastric ulcers through an imbalance of basic antioxidative- oxidative enzymes in male Wistar rats
}

\section{CURRENT STATUS: UNDER REVIEW}

BMC Research Notes $\mathbf{B} M C$ Series

Muhamudu Kalange

Kampala International University - Western Campus

Miriam Nansunga

International Hospital Kampala

Keneth Iceland Kasozi

Kampala International University - Western Campus

kicelandy@gmail.comCorresponding Author

ORCiD: https://orcid.org/0000-0002-5763-7964

Josephine Kasolo

Makerere University College of Health Sciences

Jackline Namuleme

Uzima University College

Jovile Kasande Atusiimirwe

Kampala international university

Emmanuel Tiyo Ayikobua

Kampala International University

Fred Ssempijja

Kampala International University

Edson Ireeta Munanura

Makerere University

Kevin Matama

Kampala International University - Western Campus

Ibrahim Ssemuyaba

Kampala International University - Western Campus 
Gerald Zirintunda

Busitema University

Alfred Omachonu Okpanachi

Kampala International University - Western Campus

\section{DOI:}

$10.21203 / \mathrm{rs} .2 .22004 / \mathrm{v} 1$

\section{SUBJECT AREAS}

Neurobiology of Disease

\section{KEYWORDS}

Antimalarials, Pharmacodynamics of antimalarial agents, Malaria in developing countries, Gastric ulcers 
Abstract

Objective: Antimalarials are globally used against plasmodium infections, however, information on the safety of new antimalarial combination therapies on the gastric mucosa is scarce. The aim of the study was to establish the effects of Artesunate-Amodiaquine and Artemether-Lumefantrine on gastric ulcers, malondialdehyde (MDA), reduced glutathione (GSH) and identify major histological changes in male Wistar rats. Gastric ulcers were induced using Indomethacin in four groups and group 1 was administered Artesunate, group 2 received Artesunate-Amodiaquine, group 3 received ArtemetherLumefantrine, and group 4 was a positive control (normal saline). Group five was the negative control consisting of healthy rats.

Results: Antimalarial combination therapies were associated with a high gastric ulcer index than a single antimalarial agent, Artesunate. In addition, levels of MDA were significantly higher in the combination of therapies while levels of GSH were lower in comparison to Artesunate and the negative control. Microscopically, antimalarial combination therapies were associated with severe inflammation and tissue damage than Artesunate in the gastric mucosa showing that antimalarial combination therapies exert their toxic effects through oxidative stress mechanisms, and this leads to apoptosis. Findings in this study demonstrate a new to revisit information on the pharmacodynamics of major circulating antimalarial agents in developing countries.

\section{Full-text}

Due to technical limitations, full-text HTML conversion of this manuscript could not be completed. However, the manuscript can be downloaded and accessed as a PDF.

Figures 

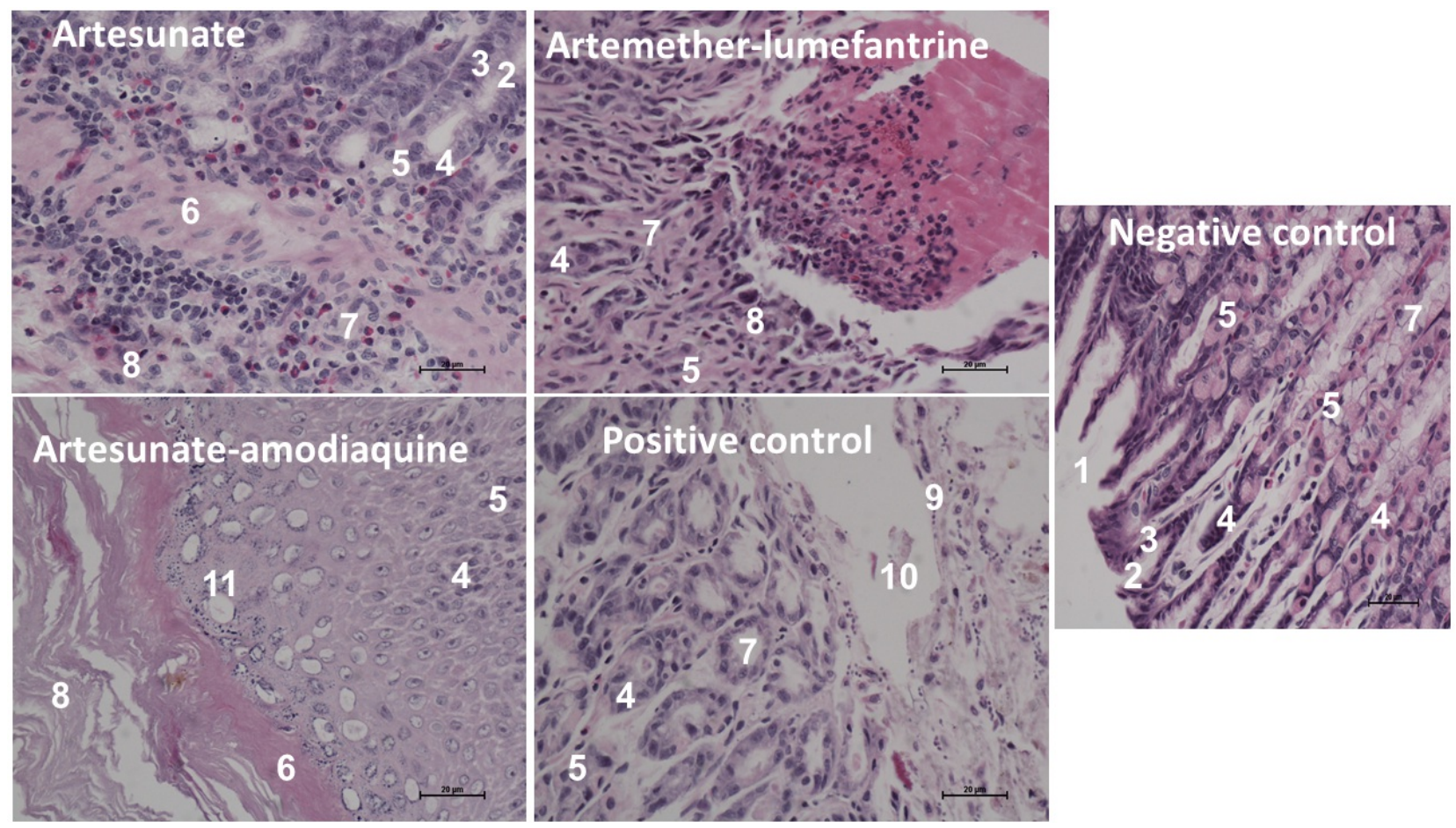

Figure 1

Variations in ulcer index, malondialdehyde and reduced glutathione in the gastric mucosa of male Wistar rats. Graphs $\mathrm{A}=$ Ulcer index $\mathrm{B}=$ concentrations of malondialdehyde and $\mathrm{C}=$ concentrations of reduced glutathione. 

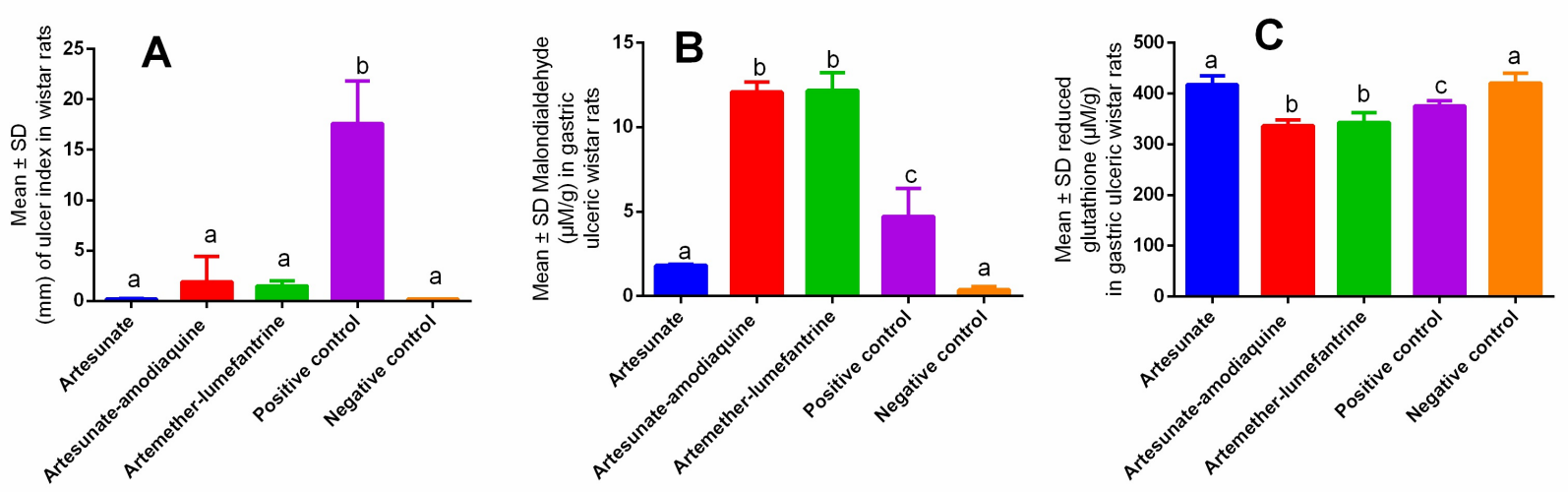

Figure 2

Histological changes in gastric mucosa and epithelia following administration of 169 common antimalarials in male Wister rats. $1=$ Gastric lumen; $2=$ Gastric pit; $3=$ Columnar

1708 epithelium; 4 = Parietal cells; $5=$ Chief cells; 6 = Lamina muscularis; $7=$ Gastric glands; 8 = Sub mucosa; $9=$ Endothelium of blood vessel; $10=$ Blood cell; $11=$ Vacoulations in nonglandular stomach.

\section{Supplementary Files}

This is a list of supplementary files associated with this preprint. Click to download.

ARRIVE CHECKLIST.docX 